\title{
Wearable Nanogenerators: Working Principle and Self-Powered Biosensors Applications
}

\author{
Helinando Pequeno de Oliveira
}

Institute of Materials Science, Universidade Federal do Vale do São Francisco, Juazeiro, BA 48920-310, Brazil;

helinando.oliveira@univasf.edu.br

check for updates

Citation: Oliveira, H.P.d. Wearable Nanogenerators: Working Principle and Self-Powered Biosensors

Applications. Electrochem 2021, 2,

118-134. https://doi.org/10.3390/ electrochem 2010010

Received: 9 February 2021

Accepted: 24 February 2021

Published: 28 February 2021

Publisher's Note: MDPI stays neutral with regard to jurisdictional claims in published maps and institutional affiliations.

Copyright: (C) 2021 by the author. Licensee MDPI, Basel, Switzerland. This article is an open access article distributed under the terms and conditions of the Creative Commons Attribution (CC BY) license (https:// creativecommons.org/licenses/by/ $4.0 /)$

\begin{abstract}
Wearable self-powered sensors represent a theme of interest in the literature due to the progress in the Internet of Things and implantable devices. The integration of different materials to harvest energy from body movement or the environment to power up sensors or act as an active component of the detection of analytes is a frontier to be explored. This review describes the most relevant studies of the integration of nanogenerators in wearables based on the interaction of piezoelectric and triboelectric devices into more efficient and low-cost harvesting systems to power up batteries or to use the generated power to identify multiple analytes in self-powered sensors and biosensors.
\end{abstract}

Keywords: triboelectric; piezoelectric; self-powered sensors; energy harvesting; wearable; textiles

\section{Introduction}

The Internet of Things [1-3] and Smart Cities [4-6] are emerging themes in the literature that require sensors integration, based on recent advances in wearable electronics, that are classified as epidermal devices and implantable devices [7], since these materials can be worn on or in the body, facilitating a plethora of applications such as the detection of toxic gases, volatile organic compounds, UV radiation on skin, and temperature monitoring. Some critical properties for these devices (such as skin integration, stretchability, and long cycle life-which have been considered intrinsic drawbacks for conventional sensors and actuators) define the type of material to be explored. In addition to these required properties, there are critical factors relative to the access level of these devices: some implantable components (particularly depleted components in batteries for cardiac pacemakers, defibrillators, deep brain stimulators) that require periodical substitution, representing a limiting aspect for implantables-regular surgeries are unnecessary risks for patients [8,9]. To circumvent the disadvantages of conventional energy storage devices (related to a limited lifetime in association to the leakage of toxic compounds into the body and physical burden), different mechanisms have been explored in the scavenge of energy from different movements (walking, jumping, running, or muscles contraction, relaxation, and cardiac motion) to reinforce the concept of self-powered sensors and power sources [1,9-15]. The overall mechanical energy involved in our daily activities is expected to reach overall power up to $67 \mathrm{~W}$ [10] that can be conveniently harvested by nanogenerators, which are classified as triboelectric and piezoelectric devices [16].

The technology of nanogenerators favors plenty of new devices such as biosensors, health-monitoring human-computer interfaces [14] (such as in the improvement of the performance of and in the detection of vital signals-specific analytes in sensors and biosensors) in addition to the improvement in the performance of electrochemical devices (energy storage systems such as supercapacitors and batteries).

In terms of sensors and biosensors, the incorporation of nanogenerators considers not only a primary role of generating energy to feed the electronics components (in prototypes of self-powered devices) but also for use as a sensing detection element that must be affected by the adsorption of the target molecules into nanogenerators. An example of this 
process is the creation of gate potential as reported by Selvarajan et al. [17] as a consequence of the interference of glucose on the flow of free electrons of nanogenerators, creating a direct relationship between the generated voltage and the amount of analyte (glucose). This process is facilitated by the modification of piezoelectric components with enzymes that interact with the analyte and modulate the generated power [18]. Consequently, the modulated potential can be explored as a potential parameter for the identification of specific components.

For monitoring physiological signals, nanogenerators represent relevant alternatives for diaphragmatic breathing monitoring in substitution to conventional sensors. The relation between output voltage from the nanogenerator and the respiration signal represents an important application for this self-powered prototype of the sensor [19].

In terms of application in energy power devices, the primary activity of energy generation has been added to an auxiliary role that refers to the association with supercapacitors in which the intermittent generation of electricity improves the energy density of wearable supercapacitors [20]. It is worth mentioning that these promising strategies to integrate nanogenerators and sensors, biosensors, and energy storage devices need to circumvent drawbacks from conventional materials such as comfort, flexibility, retention of properties under successive washing procedures, wear and tear processes, and the following improvement in the self-healing properties for the resulting material that must be integrated into a single material that potentializes these characteristics, as observed in all-in-one textile components for multifunctional devices.

Herein, we report the working principles of nanogenerators (piezo- and triboelectric devices) for the intrinsic activity of feed-up secondary batteries and supercapacitors and the potential application of chemically modified structures in the self-powered sensor's area, making use of the generated power value in the identification of traces of analytes.

\section{Working Principles}

\subsection{Piezoelectric Nanogenerators (PENGs)}

The piezoelectric process is a transductive mechanism observed under modification of the central symmetry of the crystalline structure in the response to external mechanical stress. The mechanical deformation affects the overall electric dipole orientation and induces the displacement of oppositely charged species to the surface of the material, creating an electrical potential difference (that can be explored to feed an external load) [21-24]. The efficiency of the piezoelectric generation depends on several factors, such as the material type (ceramic, single crystals, and polymers) and the direction of application of external force, with the piezoelectric-dependent current given by Equation (1), as follows [25]:

$$
I_{\text {piezo }}=d_{33} A \frac{d \sigma}{d t}
$$

where $d_{33}$ is the piezoelectric coefficient, $\mathrm{A}$ is the effective area of the device, and $\frac{d \sigma}{d t}$ is the rate of mechanical stress change. The piezoelectric coefficients for the most common materials applied in piezoelectric nanogenerators (PENGs) such as crystals, polymers, and hybrid materials are summarized in Table 1.

As can be seen, by comparison between crystal-based systems and polymer-based ones, higher $d_{33}$ coefficient values are observed for crystals. These values are also extremely dependent on the direction of mechanical effort relative to the polar axis, which is defined by the crystal orientation in non-ferroelectric materials and by the poling direction in ferroelectric materials [26]. 
Table 1. Piezoelectric coefficient values for different materials.

\begin{tabular}{ccc}
\hline Material/Type & $d_{33}$ Value, $\mathbf{p C} / \mathbf{N}$ & Ref. \\
\hline $\begin{array}{c}\mathrm{Pb}\left(\mathrm{Mg}_{1 / 3} \mathrm{Nb}_{2 / 3}\right) \mathrm{O}_{3}-\mathrm{PbTiO}_{3} \\
\mathrm{PMM}-\mathrm{PT} /(\text { ceramic) }\end{array}$ & $2000-3000$ & {$[26]$} \\
\hline $\begin{array}{c}\text { Lead zirconia titanate } \\
\text { PZT-5H/(ceramic) }\end{array}$ & 593 & {$[26]$} \\
\hline Bulk copolyimide (polymer) & 420 & {$[27]$} \\
\hline Poly(tetrafluoroethylene)_PTFE & 200 & {$[28]$} \\
\hline BaTiO3 /(ceramic) & 190 & {$[26]$} \\
\hline $\begin{array}{c}\text { Lead zirconia titanate } \\
\text { and polyvinylidene fluoride } \\
\text { PZT/PVDF/(composite) }\end{array}$ & 36 & {$[29]$} \\
\hline PVDF random fibers/(polymer) & & {$[30]$} \\
\hline ZnO/(ceramic) & 24.90 & {$[26]$} \\
\hline $\begin{array}{c}\text { Poly (L-lactic acid) } \\
\text { PLLA/(polymer) }\end{array}$ & $6-13$ & {$[26]$} \\
\hline Silk/(biomaterial) & $6-12$ & {$[26]$} \\
\hline
\end{tabular}

Despite the superior piezoelectric response observed for ceramic-based materials, the demand for wearable and truly flexible nanogenerators opens up the possibility for combined use in alternative hybrid materials based on polymers.

Polyvinylidene fluoride (PVDF) is a very common template for piezoelectric applications because of its low cost, flexibility, and characteristic ferroelectric behavior. Despite being thermodynamically stable in the $\alpha$-phase, (a non-polar component), it is possible to convert the a- to $\beta$-phase, reinforcing the ferroelectric and consequently the piezoelectric response of the material [30-33]. The incorporation of piezoelectric crystals ( $\mathrm{ZnO}$, $\mathrm{BaTiO}_{3}$, etc.) into PVDF followed by an annealing-based procedure reinforces the overall piezoelectric response (by the contribution of ceramic) and the conversion rate from $\alpha$ - to $\beta$-phase [31].

Electrospinning has been considered one of the most important processing techniques applied in the production of flexible fibers of pristine and additives-embedded polymeric templates for different applications $[34,35]$. The typical procedure for the production of electrospun fibers is based on the preparation of a polymeric solution (with a required window for specific density) that is kept under pressure in a syringe. The spinneret (the metal dip) is connected to high source voltage (in order of $20 \mathrm{kV}$ ) disposed in front of a grounded target. The high electric field established promotes the droplet deformation that favors the formation of a transition zone (Taylor's cone) from which is ejected a polymeric jet that flows in the direction of the grounded target-during this process, the solvent evaporates, allowing a solid fiber to be deposited on the target. There are several strategies to align the fibers during the production procedure (such as from the use of a rotating collector) and by thermal treatment. It is reported that under thermal treatment and with an external electric field, researchers observed an increase in the $\beta$-phase and the dipole orientation of domains of PVDF-based electrospun fibers [31]. As a result, a porous controlled structure of net fibers (with diameter distribution determined by the experimental setup conditions) can be explored as a flexible template with adequate comfort for interaction with the body.

Despite the characteristic low piezoelectric coefficient of polymers, their use in wearable PENGs (W-PENGs) is practically mandatory due to the requisites of flexibility and wearability. Based on these aspects, polyvinylidene fluoride-co-trifluoroethylene (PVDF-TrFE) [36-42] and polyvinylidene fluoride hexafluoropropylene (PVDF-HFP) [29,31,33,43-47] are preferred for use as flexible supports for PENGs. The low piezo potential of PVDF (due to the prevailing $\alpha$-phase) has been circumvented by different strategies, based on the alignment 
of dipoles, conversion to the $\beta$-phase of PVDF-based systems, and from the production of organic-inorganic composites.

The production of highly aligned nanofibers of PVDF disposed of in micropatterned interdigital electrodes is reported in Ref. [37] in prototypes that generate a signal of $150 \mathrm{~V}$ and power of $8.75 \mathrm{mWcm}^{-2}$. The alignment of boron nitride nanotubes as micropillar arrays in the $\mathrm{P}(\mathrm{VDF}-\mathrm{TrFE})$ matrix results in a voltage of $22 \mathrm{~V} \mathrm{[40].}$

The use of electrospinning as a processing technique to produce W-PENGs and the additional incorporation of additives (with high piezoelectric coefficient) by a simple solvent mixing procedure can be explored to induce good alignment of the fibers.

It is reported in Ref. [31] that the incorporation of nanotubes of $\mathrm{TiO}_{2}$ and nanoflowers of $\mathrm{ZnO}$ into PVDF-HFP fibers by the coaxial electrospinning technique favors the coaxial alignment of multiwalled carbon nanotubes on electrospun fibers of $\mathrm{P}(\mathrm{VDF}-\mathrm{TrFE})$, resulting in good piezoelectric performance $\left(\mathrm{V}=18.23 \mathrm{~V} ; \mathrm{I}=2.14 \mathrm{~mA}\right.$ and $\left.\mathrm{P}=6.53 \mathrm{mWcm}^{-2}\right)$ [38]. Piezocomposite nanogenerators have been assembled from the incorporation of rodshaped zinc ferrite in PVDF-HFP, with performance in energy generation of $(\mathrm{V}=8.5 \mathrm{~V}$; $\mathrm{I}=0.5 \mathrm{mAcm}^{-2}$ ) [48]. The in-situ poling near-field electrospinning of PVDF produced aligned piezoelectric nanogenerators with outstanding performance $(\mathrm{V}=130 \mathrm{~V} ; \mathrm{I}=4 \mathrm{~mA}$; $\mathrm{P}=8.34 \mathrm{mWm}^{-2}$ ) [49].

The reinforcement in the $\beta$-phase of PVDF-based fibers has been explored by the incorporation of core-shell nanoparticles of $\mathrm{BaTiO}_{3} @$ carbon into electrospun fibers of PVDF$\operatorname{TrFE}(\mathrm{V}=17 \mathrm{~V} ; \mathrm{P}=14.3 \mathrm{~mW}$ ) [36]. Alternatives to these systems have been reported from the combination of barium titanate with graphene nanosheets in electrospun fibers of PVDF $(\mathrm{V}=11 \mathrm{~V} ; \mathrm{P}=4.1 \mathrm{~mW})$ [50], by the direct interaction of barium titanate nanoparticles into electrospun fibers of PVDF ( $\mathrm{V}=25 \mathrm{~V}$ ) [41], or by spin-coating of barium titanate in PVDFTrFE solution into the flexible substrate that results in $\mathrm{V}=9.8 \mathrm{~V}$ and $\mathrm{P}=13.5 \mathrm{mWcm}^{-2}$ [42] The potential of $\mathrm{BaTiO}_{3}$ as an active piezoelectric has been also observed in different flexible supports such as the Ecoflex matrix. The resulting material produces an electrical response of $\mathrm{V}=8.9 \mathrm{~V}$ and a current at short circuit conditions of $49.7 \mathrm{nA}$ [51].

Specific strategies have focused on the control of the morphology of fillers-additives such as cadmium sulfide (CdS) nanowalls ( $\mathrm{I}_{\mathrm{SC}}=6 \mathrm{nA} ; \mathrm{V}_{\mathrm{OC}}=1.2 \mathrm{~V}$ ) [52], from the hydrothermal synthesis of $\mathrm{ZnO}$ nanorod arrays sandwiched between layers of silver-coated fabrics [53] $\left(\mathrm{I}_{\mathrm{SC}}=20 \mathrm{nA} ; \mathrm{V}_{\mathrm{OC}}=4 \mathrm{~V}\right)$, or by the production of zinc oxide tetrapods [54] $\left(\mathrm{I}_{\mathrm{SC}}=300 \mathrm{nA} ; \mathrm{V}_{\mathrm{OC}}=20 \mathrm{~V}\right)$. The incorporation of carbon nanotubes into barium titanatePVDF piezoelectric nanogenerators resulted in the improvement of the output voltage $\left(7.3 \mathrm{Vcm}^{-2}\right)$ for I $=3.3 \mathrm{nAcm}^{-2}$ [55].

The production of organic-inorganic composites for W-PENG has been reported by the incorporation of cellulose nanocrystals-Fe-doped nano $\mathrm{ZnO}$ in a PVDF-HFP matrix [43] $\left(\mathrm{I}_{\mathrm{SC}}=1.9 \mathrm{mAcm}^{-2} ; \mathrm{V}_{\mathrm{OC}}=12 \mathrm{~V}\right)$, by the synthesis of organic-inorganic trihalide perovskites $\left(\mathrm{I}_{\mathrm{SC}}=0.61 \mathrm{mAcm}^{-2} ; \mathrm{V}_{\mathrm{OC}}=5.9 \mathrm{~V}\right)$ [56], or by the introduction of niobium-doped $\mathrm{Pb}(\mathrm{Zr}$, $\mathrm{Ti}_{3} \mathrm{O}_{3}$ (NPZT) nanoparticles into PVDF-TrFE (V = 10 V) [39]. Despite good performance as isolated components that harvest energy from movement, the combined action of these materials represents an important strategy to be considered for new devices with outstanding performance.

\subsection{Triboelectric Nanogenerators (TENGs)}

Triboelectric nanogenerators (TENGs) were initially reported by Wang and coworkers [57]. In this inaugural communication, the authors reported the development of a flexible, low-cost, and simple triboelectric generator exploring a method in which charges were separated to favor the circulation of current through an external load. For this, a simple configuration of two different materials (such as different polymer sheets) is assembled as a disposition of parallel plates in a capacitor (air as a dielectric) with the top and the bottom surfaces coated by a metal thin layer (such as gold). The relevance of the metallic layer on polymer surfaces refers to the creation of charged mobile species 
via electrostatic induction in response to the triboelectric effects on interfaces of active materials [58].

The triboelectric generation of energy takes place from the charge separation at the interface of rough nanosurfaces that suffer mechanical compression, which is followed by the electrostatic charge separation between two surfaces that results in an interface dipole layer $[10,59,60]$. In response to this charge separation between active layers, researchers induced a density of electrostatic free charges on a metal layer that can circulate in the external circuit.

The typical configuration of electrodes in a TENG is schematically drawn in Figure 1.

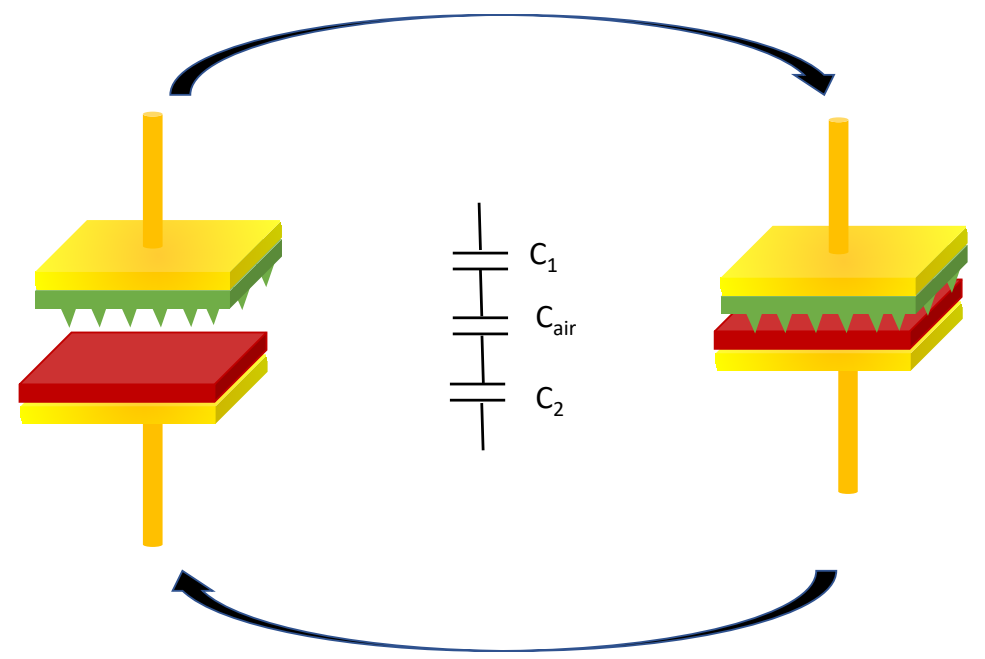

Figure 1. Schematic representation of triboelectric nanogenerator (TENG) composed of gold electrodes and two dielectrics (rough layer in green and a second polymer layer in red) and a representation of a corresponding electrical circuit.

As can be seen in Figure 1, the overall configuration of a triboelectric generator is represented from the association (in series) of three different capacitors, with each capacitance represented by a disposition of parallel plates (area A, the distance between electrodes $d_{i}$ and different dielectric (permissivity $\varepsilon_{i}$ ), which is given by:

$$
C_{1}=\varepsilon_{1} \frac{A}{d_{1}} ; \quad C_{a i r}=\varepsilon_{0} \frac{A}{d_{\text {air }}} ; \quad C_{2}=\varepsilon_{2} \frac{A}{d_{2}}
$$

with the total capacitance given by Equation (3):

$$
\frac{1}{C_{e q}}=\frac{1}{C_{1}}+\frac{1}{C_{a i r}}+\frac{1}{C_{2}}
$$

Note that under mechanical efforts, $C_{1}$ and $C_{2}$ remain unchanged, while $C_{a i r}$ varies from $C_{a i r}=\varepsilon_{0} \frac{A}{d}$ to $C^{\prime}{ }_{a i r}=\varepsilon_{0} \frac{A}{d-\delta}$ due to the variation in the distance between plates.

The resulting distribution of charges between electrodes $\left(q=C_{e q} V\right)$ favors the current circulation along with external load, as described by Equation (4):

$$
i=\frac{d q}{d t}=C_{e q} \frac{\partial V}{\partial t}+V \frac{\partial C_{e q}}{\partial t}=i_{\text {tribo }}+i_{\text {geom }}
$$

It is important to identify these two terms in the overall response of the generated current as of the triboelectric effect $\left(i_{\text {tribo }}\right)$ and by changes in the dimension of the device 
under mechanical efforts (change in the distance of electrodes from $d$ to $d-\delta$ ), resulting in a contribution of $i_{\text {geom }}$ as described by Equation (5):

$$
i_{\text {geom }}=\varepsilon_{0} A V \frac{\partial}{\partial t}\left(\frac{1}{d}\right)
$$

Under removal of the external stimulus (returning to the initial position), the tribologically generated species will be neutralized and electrostatically induced charges that will be recombined along electrodes. The friction between different materials generates electrostatic charges on the internal surface of layers, allowing that electrostatic induction to be explored to charge metal electrodes for the following step of current circulation along with an external load that plays a role in neutralizing the separated charges, reaching an equilibrium for the next step of mechanical excitation. To reach outstanding performance in the triboelectric generation (current and voltage peaks), different strategies have been combined such as from the control in the roughness degree of the electrodes, their affinity to lose or gain electrons, the relative movement of electrodes (intensity and frequency), and the wearability of the devices.

As observed, the efficiency of TENG devices depends on the capacity of active materials to scavenge the maximum in the wasted biomechanical energy into electric signals 005B [61]. The adequate separation of charges between interfaces of different materials depends primarily on the electronegativity of each one. It requires a strong contact electrification of two materials with relevant and distinct electron affinity, as a consequence of the difference in the work function of the material that remains in contact: to equalize the Fermi level of both materials, a migration of electrons is established from the material with a lower work function to the material with a higher work function [62].

The most adequate condition refers to the use of materials with a higher ability to attract electrons (becoming negatively charged) in combination with materials that effectively lose electrons (becoming positively charged) [8,58].

A summary of the most promising materials for TENGs is schematically ordered in terms of tribopositive (red arrow) and tribonegative (green arrow) behaviors shown in Figure 2, with corresponding values of charge affinity.

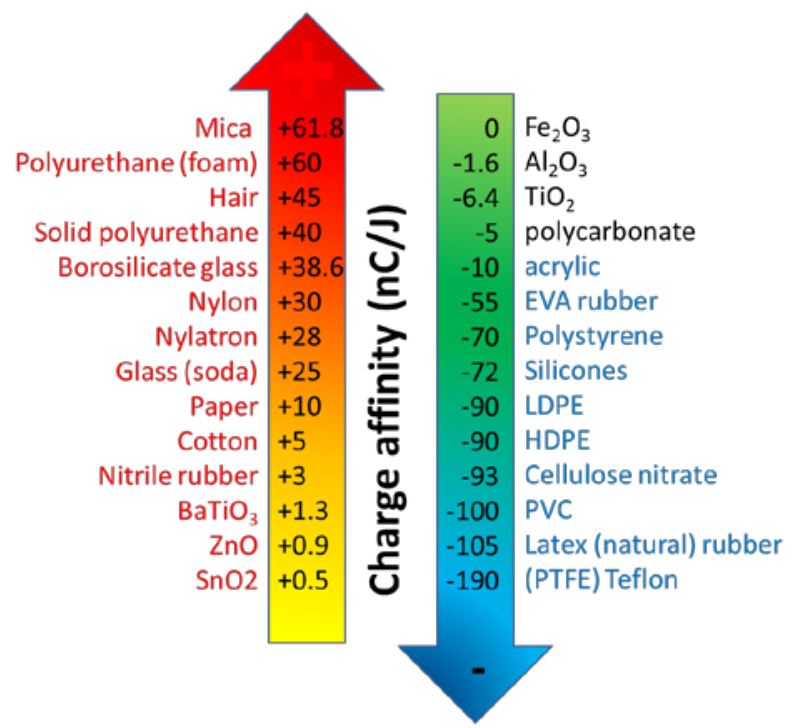

Figure 2. List of tribopositive and tribonegative materials for application in TENGs $[26,63]$.

The use of triboelectric devices with pair of materials that are classified in the extreme of the triboelectric series represents the most adequate combination of more efficient TENG devices-a higher degree of charge separation in triboelectric pairs. Another constitutive aspect that must be explored in the optimization of the performance of devices is 
the roughness degree of pairs in the friction layer that must be unaffected by successive mechanical efforts [8]. Steps of contact and the separation of triboelectric pairs favor the current circulation across an external loading element but affect the surface roughness degree of the pair. Micro-nanoscale pattern modification in soft materials (such as a polymer) under successive mechanical abrasive efforts is a drawback that has been circumvented by modification in the roughness of the metal surface (polymer-metal pair), characterizing a strategy to provide a more resistant surface against abrasion [60]. As expected, a broad range of variation in the performance of TENG devices (based on a different combination of tribopairs) can be observed from the data shown in Table 2.

Table 2. Performance of different TENGs obtained from the combination of specific tribopositive and tribonegative materials.

\begin{tabular}{|c|c|c|c|c|c|c|}
\hline $\begin{array}{l}\text { Active Material } \\
\text { (Positive) }\end{array}$ & $\begin{array}{l}\text { Active Material } \\
\text { (Negative) }\end{array}$ & Electrode & Voltage & Current & Power & Ref \\
\hline CNT & Kevlar/shear stiffening gel & - & $41.27 \mathrm{~V}$ & - & $212.90 \mathrm{~mW}$ & [64] \\
\hline Silver coated fabric & $\begin{array}{l}\text { MXene/ecoflex } \\
\text { nanocomposite }\end{array}$ & $\mathrm{Ag}$ & $800 \mathrm{~V}$ & - & $3.69 \mathrm{~mW}$ & [65] \\
\hline $\mathrm{Al}$ & $\mathrm{BCZT} / \mathrm{BiHoO}_{3}-\mathrm{PDMS}$ & $\mathrm{Al}$ & $300 \mathrm{~V}$ & - & $157 \mathrm{~mW} / \mathrm{m}^{2}$ & [66] \\
\hline $\mathrm{g}-\mathrm{C}_{3} \mathrm{~N}_{4}$ & $\begin{array}{l}\text { Biaxially oriented } \\
\text { polypropylene }\end{array}$ & $\mathrm{Al} /(\mathrm{PET}-\mathrm{ITO})$ & $10 \mathrm{~V}$ & - & - & [62] \\
\hline P4VP & PVDF-HFP & $\mathrm{Al}$ & $260 \mathrm{~V}$ & $27 \mathrm{~mA}$ & $7 \mathrm{~mW}$ & {$[8]$} \\
\hline Antimonene & Kapton & $\mathrm{Al}$ & $18 \mathrm{~V}$ & $0.22 \mathrm{~mA}$ & $15 \mathrm{~mW}$ & [67] \\
\hline $\mathrm{Al}$ & Kapton & $\mathrm{Al}$ & $3250 \mathrm{~V}$ & $44.34 \mathrm{~mA}$ & - & [68] \\
\hline CNT/silk layer & PET/ITO & - & $276 \mathrm{~V}$ & $9.2 \mathrm{~mA}$ & $317.4 \mathrm{~mW} / \mathrm{cm}^{2}$ & [69] \\
\hline Nylon fabric & PTFE fabric & $\mathrm{Al}$ & $350 \mathrm{~V}$ & $5.94 \mathrm{~mA}$ & $600 \mathrm{~mW}$ & [13] \\
\hline $\begin{array}{l}\text { Cold-rolled Al } \\
\text { species }\end{array}$ & $\begin{array}{c}\text { Fluorinated ethyelene } \\
\text { propylene (FEP) }\end{array}$ & $\mathrm{Al}$ & $180 \mathrm{~V}$ & - & $0.36 \mathrm{~mW}$ & [60] \\
\hline
\end{tabular}

As can be seen, extremely high voltage (in the order of $3250 \mathrm{~V}$ ) [68] can be observed in TENG devices for applications in prototypes that combine improved performance in energy conversion with criteria of comfort due to the interaction with the body in wearable devices.

The basic requisite for the development of wearable nanogenerators (tribo and piezo) devices depends on a series of factors such as stretchability, breathability, washability, and efficiency for the conversion of energy movement into electrical energy. The strategy for the production of wearable TENGs (W-TENGs) [35,70-75] concerns the integration of triboelectric pairs into the clothes or on the skin as tattoos. Typically, there are two different general strategies to produce W-TENGS: by integrating conductive yarns in knitted nanogenerators or by the production of the skin-inspired TENGs (artificial skin).

In both cases (by the development of new materials for fabrics or by the production of biological-based TENG systems), electrospinning assumes a special position as a processing technique applied in the production of flexible and pore-rich structures $[35,76]$. The low cost for the massive production of fiber nets from polymer solutions and the simple strategy to incorporate additives into electrospun fibers are clear advantages for this technique, which has been combined with different strategies to provide superior properties for resulting devices, and it is described as follows.

The facility for processing, low-cost, and ferroelectric properties makes the PVDF $[8,30,33,77-80]$ a strong candidate for use in electrospinning assays for the production of flexible and crystalline-type structures. The response of these electrospun fibers can be improved by additional steps such as electrospraying additives (for example, elastic binders that enhance the stretchability, as reported in Ref. [33], in which researchers observed an open circuit voltage $\left(\mathrm{V}_{\mathrm{O}}\right)$ of $85 \mathrm{~V}$ and power of $219.66 \mathrm{mWm}^{-2}$ ) or by the use of print-ink nanofillers to increase the crystallinity of 
PVDF (higher $\beta$-phase amount) with reported power in the order of $22 \mathrm{Wm}^{-2}$ [77]. Another possibility concerns the production of composites by impregnation with active carbon [78] to reach desirable electrical properties for use in TENGs.

Alternatives to the use of PVDF in textiles refer to the wrapping of metal nanostructures (such as Ag conductive yarns) in polytetrafluoroethylene (PTFE) and nylon [81] (that reaches a power density of $7.531 \mathrm{mWm}^{-2}$ under compression) or by chemical modification of the silk-based films. As reported in Ref. [82], regenerated silk fibroin is chemically functionalized by the incorporation of glycerol and polyurethane to act as a friction electrode acquiring properties of artificial skin, reaching a power of $0.8 \mathrm{Wm}^{-2}$. The production of samples combining the electrospray of silk and carbon nanotubes represents another possibility to develop electrodes for W-TENGs with good electrical conductivity, flexibility, and desirable properties for wearables.

On the other hand, skin-inspired TENGs depend on the production of composites electrodes with skin-like compliance that is reached by the electrospinning of materials such as thermoplastic polyurethane followed by the electrospray deposition of AgNWs $\left(\mathrm{Voc}=95 \mathrm{~V} ; \mathrm{I}_{\mathrm{SC}}=0.3 \mathrm{~mA}\right.$; and $\left.\mathrm{P}=6 \mathrm{mWm}^{-2}\right)$ [76], by the deposition of liquid metal droplets on elastomers [83], or by the incorporation of thin gold layers on elastomeric substrates for the development of ultra-stretchable devices $\left(150 \mathrm{mWm}^{-2}\right)$ [73].

The incorporation of $\mathrm{v}$-AuNWs represents another important strategy in the production of single electrode design with a special interest in tattoo-like-based electrode applications [58] in which devices are directly transferred to the skin or elastomeric substrates (Ecoflex: PTFE) [73]. The conventional assembly of tribonegative and tribopositive materials has been explored for wearable devices from the use of $\mathrm{Al}_{2} \mathrm{O}_{3}$ nanofillers into cellulose acetate for the posterior deposition on conductive fibers [84], reaching outstanding performance $\left(\mathrm{V}_{\mathrm{OC}}=448 \mathrm{~V}\right.$ and $\left.\mathrm{P}=2.5 \mathrm{mWcm}^{-2}\right)$ [84].

\subsection{Hybrid Wearable Nanogenerators}

The production of hybrid nanogenerators for wearables opens possibilities to compensate shortcomings from each type of nanogenerator in a more efficient energy-capture process from multiple sources.

There are different possibilities of combination for energy harvesting systems that resulted in the production of hybrid devices, such as triboelectric-piezoelectric generators [72,85-97], triboelectric-thermoelectric generators [98,99], photovoltaic-triboelectric generators [100,101], UV photovoltaic - piezoelectric generators [102], electromagnetictriboelectric generators [103-105], electromagnetic-triboelectric-piezoelectric generators [106,107], photovoltaic - piezoelectric generators [108], and piezoelectric-pyroelectric generators [25].

The general idea involved in hybrid generators in wearables is based on the successive deposition of overlaid layers of the active materials and electrodes that are simultaneously excited by different sources (electromagnetic, heat, wind, pressure, or contact). Especially for wearables, the most common association of nanogenerators is observed for the combination of triboelectric and piezoelectric devices in which materials with a high piezoelectric coefficient $\left(\mathrm{BaTiO}_{3}\right.$ and $\left.\mathrm{BCTZ}\right)$ are combined with materials with desirable electron affinity to reach outstanding tribo-based pairs. The operation of devices is based on the independent activity of devices or by the integration of components into truly hybrid devices that are schematically drawn in Figure 3. 


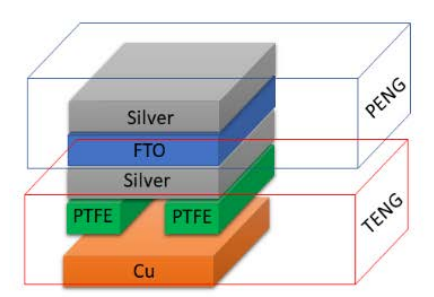

(a)

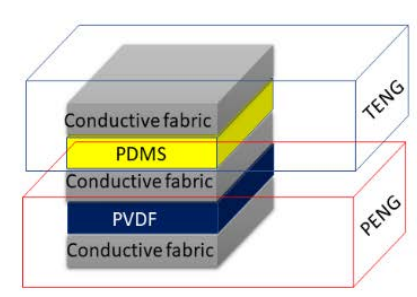

(b)

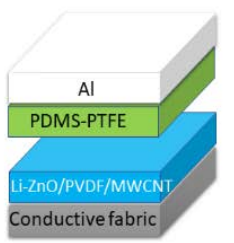

(c)

Figure 3. Schematic view of hybrid devices integrating triboelectricity and piezoelectricity with separated (TENG-PENG) configuration (a) Ref. [85] and (b) Ref. [97] or mixed configuration (c) Ref. [94]. PENG: piezoelectric nanogenerators.

As shown in Figure 3a,b, the hybrid generators are typically assembled by the successive deposition of layers as isolated elements or in an integrated disposition of components that share the same electrodes (in a minimal configuration of two electrodes and two active layers (see Figure 3c)).

In this configuration, the direct contact of a triboelectric layer (PDMS-PTFE) with the piezoelectric film ( $\mathrm{Li}-\mathrm{ZnO} / \mathrm{PVDF} / \mathrm{MWCNT}$ ) sandwiched between electrodes ( $\mathrm{Al}$ and $\mathrm{Ag}$ ) makes use of both mechanisms, introducing a reduction in costs (if we consider the use of additional conductive layers explored as electrodes).

The performance of hybrid nanogenerators, which integrate different mechanisms for scavenging energy to reach outstanding performance in energy generation, is summarized in Table 3.

The good performance of PVDF-based hybrid (piezo- and tribo-) electric devices has been observed in Table 3 with outstanding performance for devices that present open circuit voltage higher than $100 \mathrm{~V}$, characterizing the polymeric matrix (pristine and combined with ceramic nanoparticles) as a promising template for incorporation in wearable electronics. For use as a pristine matrix, the vertically stacking of symmetric devices based on PVDF makes use of its characteristic negative piezoelectricity and triboelectricity behavior associated with the electric polarization favored by the $\beta$-phase to reach a device in which the PVDF acts as a piezoelectric and triboelectric active layer-the symmetrical disposition of identical and piled up layers introduces advantages for the continuous conversion of energy from pressing (piezoelectric current) and release (triboelectric contribution for the current) [90]. The optimization in the performance of W-TENGs and W-PENGs is critically important for the application of these systems in a diversity of fields such as electronic skin or self-powered sensors and biosensors, which are described in the following section. 
Table 3. Description of hybrid nanogenerators and corresponding performance in devices.

\begin{tabular}{|c|c|c|c|c|c|}
\hline Hybrid Nanogenerator & Active Material & Potential (V) & Power & Current & Ref \\
\hline Triboelectric- Piezoelectric & PTFE-Barium titanate & 45 & - & $10.4 \mathrm{mAcm}^{-2}$ & [85] \\
\hline Triboelectric- Thermoelectric & $\begin{array}{c}\text { Polyimide/PDMS- } \\
\mathrm{Bi}_{2} \mathrm{Te}_{3}\end{array}$ & 30.5 & $24.34 \mathrm{mWm}^{-2}$ & $1.98 \mathrm{~mA}$ & [98] \\
\hline Triboelectric- Piezoelectric & PVDF & - & $127 \mathrm{~mW}$ & & [90] \\
\hline Triboelectric- Piezoelectric & $\begin{array}{l}\mathrm{Ba}\left(\mathrm{Ti}_{0.8} \mathrm{Zr}_{0.2}\right) \mathrm{O}_{3}-\left(\mathrm{Ba}_{0.838}\right. \\
\left.\mathrm{Ca}_{0.162}\right)\left(\mathrm{Ti}_{0.9072} \mathrm{Zr}_{0.092}\right) \mathrm{O}_{3}\end{array}$ & 45 & - & $2.8 \mathrm{~mA}$ & [91] \\
\hline Triboelectric- Piezoelectric & $\begin{array}{c}\text { Nitrocellulose/MWCNT- } \\
\mathrm{BaTiO}_{3}\end{array}$ & 18 & - & $1.6 \mathrm{mAcm}^{-2}$ & [92] \\
\hline $\begin{array}{l}\text { Triboelectric- } \\
\text { Piezoelectric- } \\
\text { Electromagnetic }\end{array}$ & $\begin{array}{c}\text { Kapton-Nylon-PTFE- } \\
\text { Magnet }\end{array}$ & 30 & - & - & [106] \\
\hline Triboelectric- Piezoelectric & Kapton-PVDF & 560 & $3.7 \mathrm{Wm}^{-2}$ & - & [93] \\
\hline Triboelectric- Piezoelectric & $\begin{array}{c}\text { PDMS-PTFE- } \\
\text { PVDF-Li-ZnO-MWCNT }\end{array}$ & 60.1 & - & $75 \mathrm{~mA}$ & [94] \\
\hline $\begin{array}{l}\text { Photovoltaic - } \\
\text { Piezoelectric }\end{array}$ & Conventional solar cell-PVDF & 5.071 & $3.42 \mathrm{~mW}$ & $1.282 \mathrm{~mA}$ & [108] \\
\hline Triboelectric- Piezoelectric & $\begin{array}{c}\text { PDMS-MWCNT-PVDF- } \\
\text { CNT-BaTiO } \\
\end{array}$ & 161.66 & $2.22 \mathrm{Wm}^{-2}$ & - & [97] \\
\hline Triboelectric- Piezoelectric & Silk fibroin-PVDF & 500 & $0.31 \mathrm{mWcm}^{-2}$ & $12 \mathrm{~mA}$ & [86] \\
\hline
\end{tabular}

\section{Self-Powered Biosensors Based on Nanogenerators}

The advances in the technology of self-powered biosensors are observed from the diversity of new experimental systems applied as skin-patch sensors, which explore different mechanisms to detect diseases, viruses, and bacteria. These mechanisms are based on electrochromic sensing [109], photochemical [110], electrochemical [111-113], enzymatic biofuel cell sensing [114], and piezoelectric/triboelectric-based nanogenerators that can be explored as either power sources or active sensors [115].

The standard procedure to reach an autonomous condition for biosensors refers to the use of potential piezoelectric materials (zinc oxide, lead zirconate titanate, polyvinylidene fluoride, and barium titanate) as active layers that separate charges and generate energy (current circulation) under pressure [116] to charge conventional batteries or to directly power biosensors [117] (as described in the previous sections). However, in more efficient assays, the use of nanogenerators as active elements in self-powered biosensors is typically observed from the modification of active material with enzymes that capture specific analytes. This process affects the overall efficiency of energy generation of nanogenerators that can be explored as a method for the detection and quantification of analytes. Nanogenerators have been progressively applied in the detection of glucose and thrombin, and they can be considered as promising candidates for COVID detection and inhibition.

\subsection{Glucose Detection}

The standard role for nanogenerators in glucose detectors as a power source has been mutually explored for triboelectricity and piezoelectric assemblies, with the development of wearable structures in which generated power is used to activate the electronic circuit of conventional biosensors from stored energy in batteries and supercapacitors. The typical modification in piezoelectric assembly for the direct detection of glucose concentration in a fluid has been reported in the literature by the modification of piezoelectric devices with glucose oxidase. Ref. [118] reported the preparation of glucose-oxidase @ ZnO arrays as active elements for electronic skin prototypes that are sandwiched between electrodes of $\mathrm{Ti}$ with a PDMS-coated layer and PDMS-Al layer. The response of the modified nanogenerator is mutually dependent on the pressure and the glucose concentration due to the combined response of surface enzymatic reaction and the piezoelectric behavior of the resulting 
structure. Based on these factors, it is possible to determine the glucose concentration from variation in the piezoelectric potential generated at a specific pressure.

\subsection{Thrombin Detection}

The thrombin detection is conveniently explored from modification in the standard configuration of conventional triboelectric nanogenerators. The simple functionalization of gold nanoparticles and the reasonable activity of these particles to be explored as active layers in triboelectric pairs are the benefits of this application.

Jung et al. [119] described the preparation of a positively charged dispersion of gold nanoparticles deposited on $\mathrm{Al}$ film to form a triboelectric pair. The selective identification of thrombin was favored by the incorporation of anti-thrombin aptamers on the gold nanoparticles that enables the specific binding with thrombin. As a consequence of specific binding with specific molecules, researchers observed a direct variation in the generated electrical signal. A limit of detection of $0.41 \mathrm{nM}$ and a simple method of detection by commercial LED lights was explored by the authors. As an alternative, modification in piezoelectric active layers is reached by aptamer modification in acoustic membrane microparticle detection assays, as reported in Ref. [120].

\subsection{SARS-COV-2 Detection}

Three different methods have been recognized for biosensors applied in coronavirus detection: electrochemical, optical, and piezoelectric-based processes. The pandemic condition reinforces the urgent development of biosensing platforms for point-of-care diagnostics, indicating that simple, low-cost, and self-powered templates are preferable to reach a sufficient number of clinical assays.

In terms of piezoelectric detection of the virus, the standard method refers to the use of piezoelectric quartz crystal that changes the characteristic frequency variation under changes in the mass of the active element. This variation is a consequence of the retention of target molecules on the immobilized receptor with specific ligands [121].

Intending to reach an adequate structure for wearable piezoelectric biosensors for SARS-COV-2, graphene-related materials represent promising templates [122] for the detection and as an antiviral agent. In this direction, the production of face masks is favored by the assembly of graphene in nanofoams.

On the other hand, due to the abundance of the groups - $\mathrm{COOH}$ in the SARS-COV2 [122], it is expected that composites of metal ions and graphene can be efficiently explored to limit the lifetime of the virus and in the detection, based on observation of the attachment of antibodies and antigens on the graphene layer. These positive aspects reinforce the possibility of the production of an all-graphene device in which carbon derivatives are explored for the design of both electrodes and active elements for COV-SARS-2 detection from the microbalance biosensor methodology [122].

\section{Challenges and Future Perspectives}

Self-powered sensing devices and integrated autonomous systems technologies for wearables are strongly dependent on the integration of energy harvesters with energy storage systems and sensors from strategies that are described as follows:

(i) The production of polymeric templates (or materials with corresponding flexibility) with outstanding piezoelectric and triboelectric coefficients;

(ii) The incorporation of energy harvesting systems in all-in-one textile devices with batteries and supercapacitors;

(iii) The incorporation of antigens and specific binders in piezo- and triboelectricity nanogenerators to reach a desirable condition of point-of-care detection of viruses;

(iv) The reduction in the costs for the massive production of energy harvesting and self-powered sensors.

The typical limitation in piezoelectric potential from polymer-based substrates has been circumvented by the development of novel piezoelectric bulk copolyimides (out- 
standing piezoelectric coefficient $d_{33}=420 \mathrm{pCN}^{-1}$ ) [27]. Based on this, the production of high-performance materials can be explored from the assembly of new devices that combine the conversion of energy from different sources. Li et al. [123] reported a wearable solar-thermal-pyroelectric harvester based on polyethyleneimine (PEI) modified by reduced graphene oxide and a pyroelectric layer of polarized PVDF film, reaching an outstanding power of $21.3 \mathrm{mWm}^{-2}$ [123].

The incorporation of hybrid nanogenerators and energy storage devices represents another important topic to be explored in the literature. For this, different prototypes have been proposed, such as observed in Ref. [72], which describes the integration of a textile TENG connected to a lithium-ion battery. As alternatives for lithium-free energy storage devices, there are efforts to incorporate supercapacitors in textiles. The most promising systems for these textile-based electrochemical storage devices are conducting polymers (such as polypyrrole [124-126] and polyaniline [127]) that can be explored as electrodes based on pseudocapacitive materials with high conductivity that preserves the intrinsic mechanical properties of the textile used as a template. Shi et al. [128] reported the production of a cellulose paper/polypyrrole composite with characteristic high conductivity (sufficient to substitute conventional metal electrodes) to act as a positive friction material for use as a triboelectric material integrated with a supercapacitor. The simple procedure for the chemical deposition of polypyrrole on textiles has been explored for the production of multifunctional devices (supercapacitors, Joule heaters [126], and single-electrode-mode TENG [129]). For this, the production of composites with polymer templates such as PDMS [130], PTFE [131], and PVDF [132] represents the possibility of reaching desirable conditions in terms of conductivity (in a free-metal electrode) and piezoelectric-triboelectric conditions to be integrated with textile-based energy storage devices exploring the same building blocks. The frontier of knowledge in wearables considers that all-in-one textile-based devices can be strongly favored by metal-free and integrated electrodes that can simultaneously harvest and store energy to feed all of the electronic circuits for the monitoring and transmission of data in self-powered systems. All of these possibilities and the improvement in the performance of nanogenerators are required to reach desirable conditions for the detection level of multiple viruses by simple, wearable, and self-powered biosensors. It is a necessary condition that paves the way to direct the research in smart sensors. The role of nanogenerators as harvesting systems and active elements for virus detection requires important parameters that are applied in the complete process of identification and communication of data.

\section{Conclusions}

The development of more efficient wearable nanogenerators based on triboelectric and piezoelectric principles is strongly dependent on strategies that combine highly efficient fillers (nanoparticles) in comfortable (and stretchable) polymeric substrates that efficiently convert mechanical movement in energy. The incorporation of aptamers and specific binders in active layers of nanogenerators represents an important step to reach a condition of complete autonomy for the detection of specific analytes. The development of more reliable sensors with higher sensitivity and accuracy in prototypes with smaller size and weight with associated low cost are some of the frontiers to be achieved in advanced and integrated biosensors based on nanogenerators.

Funding: This work was supported by Conselho Nacional de Desenvolvimento Científico e Tecnológico $(\mathrm{CNPq})$.

Institutional Review Board Statement: Not applicable.

Informed Consent Statement: Not applicable.

Data Availability Statement: Data sharing not applicable.

Acknowledgments: Brazilian agencies CNPq, FINEP, FACEPE, FAPESB, and CAPES.

Conflicts of Interest: The author declares no conflict of interest. 


\section{References}

1. Kim, W.G.; Han, J.K.; Tcho, I.W.; Park, J.Y.; Yu, J.M.; Choi, Y.K. Triboelectric Nanogenerator for a Repairable Transistor with Self-Powered Electro-Thermal Annealing. Nano Energy 2020, 76, 105000. [CrossRef]

2. Miorandi, D.; Sicari, S.; De Pellegrini, F.; Chlamtac, I. Internet of Things: Vision, Applications and Research Challenges. Ad Hoc Netw. 2012, 10, 1497-1516. [CrossRef]

3. Da Xu, L.; He, W.; Li, S. Internet of Things in Industries: A Survey. IEEE Trans. Ind. Inform. 2014, 10, 2233-2243. [CrossRef]

4. Wu, Z.; Cheng, T.; Wang, Z.L. Self-Powered Sensors and Systems Based on Nanogenerators. Sensors 2020, 20, 2925. [CrossRef]

5. Batty, M.; Axhausen, K.W.; Giannotti, F.; Pozdnoukhov, A.; Bazzani, A.; Wachowicz, M.; Ouzounis, G.; Portugali, Y. Smart Cities of the Future. Eur. Phys. J. Spec. Top. 2012, 214, 481-518. [CrossRef]

6. Zanella, A.; Bui, N.; Castellani, A.; Vangelista, L.; Zorzi, M. Internet of Things for Smart Cities. IEEE Internet Things J. 2014, 1, 22-32. [CrossRef]

7. Al Mamun, M.A.; Yuce, M.R. Recent Progress in Nanomaterial Enabled Chemical Sensors for Wearable Environmental Monitoring Applications. Adv. Funct. Mater. 2020, 30, 2005703. [CrossRef]

8. Ho, D.H.; Han, J.; Huang, J.; Choi, Y.Y.; Cheon, S.; Sun, J.; Lei, Y.; Park, G.S.; Wang, Z.L.; Sun, Q.; et al. $\beta$-Phase-Preferential Blow-Spun Fabrics for Wearable Triboelectric Nanogenerators and Textile Interactive Interface. Nano Energy 2020, 77, 105262. [CrossRef]

9. Jiang, L.; Yang, Y.; Chen, Y.; Zhou, Q. Ultrasound-Induced Wireless Energy Harvesting: From Materials Strategies to Functional Applications. Nano Energy 2020, 77, 105131. [CrossRef]

10. Zou, Y.; Raveendran, V.; Chen, J. Wearable Triboelectric Nanogenerators for Biomechanical Energy Harvesting. Nano Energy 2020, 77, 105303. [CrossRef]

11. Lin, Z.; Chen, J.; Yang, J. Recent Progress in Triboelectric Nanogenerators as a Renewable and Sustainable Power Source. J. Nanomater. 2016, 2016, 1-24. [CrossRef]

12. Wang, J.; Li, S.; Yi, F.; Zi, Y.; Lin, J.; Wang, X.; Xu, Y.; Wang, Z.L. Sustainably Powering Wearable Electronics Solely by Biomechanical Energy. Nat. Commun. 2016, 7, 12744. [CrossRef] [PubMed]

13. Paosangthong, W.; Torah, R.; Beeby, S. Textile-Based Freestanding Triboelectric-Layer Nanogenerator with Alternate Positive and Negative Grating Structure. J. Phys. Conf. Ser. 2019, 1407. [CrossRef]

14. Li, Z.; Zheng, Q.; Wang, Z.L.; Li, Z. Nanogenerator-Based Self-Powered Sensors for Wearable and Implantable Electronics. Research 2020, 2020, 1-25. [CrossRef] [PubMed]

15. Shi, B.; Liu, Z.; Zheng, Q.; Meng, J.; Ouyang, H.; Zou, Y.; Jiang, D.; Qu, X.; Yu, M.; Zhao, L.; et al. Body-Integrated Self-Powered System for Wearable and Implantable Applications. ACS Nano 2019, 13, 6017-6024. [CrossRef] [PubMed]

16. Zou, Y.; Liao, J.; Ouyang, H.; Jiang, D.; Zhao, C.; Li, Z.; Qu, X.; Liu, Z.; Fan, Y.; Shi, B.; et al. A Flexible Self-Arched Biosensor Based on Combination of Piezoelectric and Triboelectric Effects. Appl. Mater. Today 2020, 20, 100699. [CrossRef]

17. Selvarajan, S.; Alluri, N.R.; Chandrasekhar, A.; Kim, S.J. Unconventional Active Biosensor $\mathrm{Made}_{\text {of }} \mathrm{Piezoelectric} \mathrm{BaTiO}_{3}$ Nanoparticles for Biomolecule Detection. Sens. Actuators B Chem. 2017, 253, 1180-1187. [CrossRef]

18. Mao, Y.; Yue, W.; Zhao, T.; Shen, M.L.; Liu, B.; Chen, S. A Self-Powered Biosensor for Monitoring Maximal Lactate Steady State in Sport Training. Biosensors 2020, 10, 75. [CrossRef]

19. Liu, Z.; Zhang, S.; Jin, Y.M.; Ouyang, H.; Zou, Y.; Wang, X.X.; Xie, L.X.; Li, Z. Flexible Piezoelectric Nanogenerator in Wearable Self-Powered Active Sensor for Respiration and Healthcare Monitoring. Semicond. Sci. Technol. 2017, 32, 064004. [CrossRef]

20. Xiong, W.; Hu, K.; Li, Z.; Jiang, Y.; Li, Z.; Li, Z.; Wang, X. A Wearable System Based on Core-Shell Structured Peptide-Co9S8 Supercapacitor and Triboelectric Nanogenerator. Nano Energy 2019, 66, 104149. [CrossRef]

21. Zhu, Q.; Li, Y.; He, Y.; Guan, M. Piezoelectric Energy Harvesting in Automobiles. Ferroelectrics 2014, 467, 33-41. [CrossRef]

22. Nilsson, E.; Mateu, L.; Spies, P.; Hagstrom, B. Energy Harvesting from Piezoelectric Textile Fibers. Procedia Eng. 2014, 87, 1569-1572. [CrossRef]

23. Dakua, I.; Afzulpurkar, N. Piezoelectric Energy Generation and Harvesting at the Nano-Scale: Materials and Devices. Nanomater. Nanotechnol. 2013, 3, 21. [CrossRef]

24. Sirohi, J.; Mahadik, R. Piezoelectric Wind Energy Harvester for Low-Power Sensors. J. Intell. Mater. Syst. Struct. 2011, 22, 2215-2228. [CrossRef]

25. You, M.H.; Wang, X.X.; Yan, X.; Zhang, J.; Song, W.Z.; Yu, M.; Fan, Z.Y.; Ramakrishna, S.; Long, Y.Z. A Self-Powered Flexible Hybrid Piezoelectric-Pyroelectric Nanogenerator Based on Non-Woven Nanofiber Membranes. J. Mater. Chem. A 2018, 6, 3500-3509. [CrossRef]

26. Dong, L.; Jin, C.; Closson, A.B.; Trase, I.; Richards, H.R.; Chen, Z.; Zhang, J.X.J. Cardiac Energy Harvesting and Sensing Based on Piezoelectric and Triboelectric Designs. Nano Energy 2020, 76, 105076. [CrossRef]

27. Yang, L.; Chi, S.; Dong, S.; Yuan, F.; Wang, Z.; Lei, J.; Bao, L.; Xiang, J.; Wang, J. Preparation and Characterization of a Novel Piezoelectric Nanogenerator Based on Soluble and Meltable Copolyimide for Harvesting Mechanical Energy. Nano Energy 2020, 67, 104220. [CrossRef]

28. Gong, S.; Zhang, B.; Zhang, J.; Wang, Z.L.; Ren, K. Biocompatible Poly(Lactic Acid)-Based Hybrid Piezoelectric and Electret Nanogenerator for Electronic Skin Applications. Adv. Funct. Mater. 2020, 30, 30. [CrossRef]

29. Malmonge, L.F.; Malmonge, J.A.; Sakamoto, W.K. Study of Pyroelectric Activity of PZT/PVDF-HFP Composite. Mater. Res. 2003, 6, 469-473. [CrossRef] 
30. Guo, H.-F.; Li, Z.-S.; Dong, S.-W.; Chen, W.-J.; Deng, L.; Wang, Y.-F.; Ying, D.-J. Piezoelectric PU/PVDF Electrospun Scaffolds for Wound Healing Applications. Colloids Surf. B Biointerfaces 2012, 96, 29-36. [CrossRef]

31. Ponnamma, D.; Chamakh, M.M.; Alahzm, A.M.; Salim, N.; Hameed, N.; Almaadeed, M.A.A. Core-Shell Nanofibers of Polyvinylidene Fluoride-Based Nanocomposites as Piezoelectric Nanogenerators. Polymers 2020, 12, 2344. [CrossRef]

32. Mago, G.; Kalyon, D.M.; Fisher, F.T. Membranes of Polyvinylidene Fluoride and PVDF Nanocomposites with Carbon Nanotubes via Immersion Precipitation. J. Nanomater. 2008, 2008. [CrossRef]

33. Li, Y.; Xiong, J.; Lv, J.; Chen, J.; Gao, D.; Zhang, X.; Lee, P.S. Mechanically Interlocked Stretchable Nanofibers for Multifunctional Wearable Triboelectric Nanogenerator. Nano Energy 2020, 78, 105358. [CrossRef]

34. De A. B. Barbosa, J.; dos Santos, M.R.; de Oliveira, H.P. Electrospun Fibers of Copolymers for the Removal of Ionic Dyes: The Influence of Processing Variables. Fibers Polym. 2018, 19, 94-104. [CrossRef]

35. Huang, T.; Wang, C.; Yu, H.; Wang, H.; Zhang, Q.; Zhu, M. Human Walking-Driven Wearable All-Fiber Triboelectric Nanogenerator Containing Electrospun Polyvinylidene Fluoride Piezoelectric Nanofibers. Nano Energy 2014, 14, 226-235. [CrossRef]

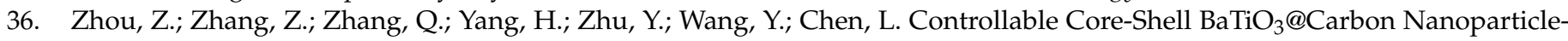
Enabled P(VDF-TrFE) Composites: A Cost-Effective Approach to High-Performance Piezoelectric Nanogenerators. ACS Appl. Mater. Interfaces 2020, 12, 1567-1576. [CrossRef]

37. Zhang, L.; Gui, J.; Wu, Z.; Li, R.; Wang, Y.; Gong, Z.; Zhao, X.; Sun, C.; Guo, S. Enhanced Performance of Piezoelectric Nanogenerator Based on Aligned Nanofibers and Three-Dimensional Interdigital Electrodes. Nano Energy 2019, 65. [CrossRef]

38. Zhao, C.; Niu, J.; Zhang, Y.; Li, C.; Hu, P. Coaxially Aligned MWCNTs Improve Performance of Electrospun P(VDF-TrFE)-Based Fibrous Membrane Applied in Wearable Piezoelectric Nanogenerator. Compos. Part B Eng. 2019, 178, 107447. [CrossRef]

39. Gupta, S.; Bhunia, R.; Fatma, B.; Maurya, D.; Singh, D.; Prateek, P.; Gupta, R.; Priya, S.; Gupta, R.K.; Garg, A. Multifunctional and Flexible Polymeric Nanocomposite Films with Improved Ferroelectric and Piezoelectric Properties for Energy Generation Devices. ACS Appl. Energy Mater. 2019, 2, 6364-6374. [CrossRef]

40. Ye, S.; Cheng, C.; Chen, X.; Chen, X.; Shao, J.; Zhang, J.; Hu, H.; Tian, H.; Li, X.; Ma, L.; et al. High-Performance Piezoelectric Nanogenerator Based on Microstructured P(VDF-TrFE)/BNNTs Composite for Energy Harvesting and Radiation Protection in Space. Nano Energy 2019, 60, 701-714. [CrossRef]

41. Siddiqui, S.; Kim, D.I.; Roh, E.; Duy, L.T.; Trung, T.Q.; Nguyen, M.T.; Lee, N.E. A Durable and Stable Piezoelectric Nanogenerator with Nanocomposite Nanofibers Embedded in an Elastomer under High Loading for a Self-Powered Sensor System. Nano Energy 2016, 30, 434-442. [CrossRef]

42. Siddiqui, S.; Kim, D., II; Duy, L.T.; Nguyen, M.T.; Muhammad, S.; Yoon, W.S.; Lee, N.E. High-Performance Flexible Lead-Free Nanocomposite Piezoelectric Nanogenerator for Biomechanical Energy Harvesting and Storage. Nano Energy 2015, 15, 177-185. [CrossRef]

43. Ponnamma, D.; Parangusan, H.; Tanvir, A.; AlMa'adeed, M.A.A. Smart and Robust Electrospun Fabrics of Piezoelectric Polymer Nanocomposite for Self-Powering Electronic Textiles. Mater. Des. 2019, 184, 108176. [CrossRef]

44. Tian, X.; Jiang, X. Poly(Vinylidene Fluoride-Co-Hexafluoropropene) (PVDF-HFP) Membranes for Ethyl Acetate Removal from Water. J. Hazard. Mater. 2008, 153, 128-135. [CrossRef]

45. Abbrent, S.; Plestil, J.; Hlavata, D.; Lindgren, J.; Tegenfeldt, J.; Wendsjö, Å. Crystallinity and Morphology of PVdF-HFP-Based Gel Electrolytes. Polymer 2001, 42, 1407-1416. [CrossRef]

46. Cao, J.H.; Zhu, B.K.; Xu, Y.Y. Structure and Ionic Conductivity of Porous Polymer Electrolytes Based on PVDF-HFP Copolymer Membranes. J. Membr. Sci. 2006, 281, 446-453. [CrossRef]

47. Parangusan, H.; Ponnamma, D.; Al-Maadeed, M.A.A. Stretchable Electrospun PVDF-HFP/Co-ZnO Nanofibers as Piezoelectric Nanogenerators. Sci. Rep. 2018, 8, 1-11. [CrossRef] [PubMed]

48. Chinya, I.; Pal, A.; Sen, S. Flexible, Hybrid Nanogenerator Based on Zinc Ferrite Nanorods Incorporated Poly(Vinylidene Fluoride-Co-Hexafluoropropylene) Nanocomposite for Versatile Mechanical Energy Harvesting. Mater. Res. Bull. 2019, 118, 110515. [CrossRef]

49. Chen, C.Y.; Tsai, C.Y.; Xu, M.H.; Wu, C.T.; Huang, C.Y.; Lee, T.H.; Fuh, Y.K. A Fully Encapsulated Piezoelectric-Triboelectric Hybrid Nanogenerator for Energy Harvesting from Biomechanical and Environmental Sources. Express Polym. Lett. 2019, 13, 533-542. [CrossRef]

50. Shi, K.; Sun, B.; Huang, X.; Jiang, P. Synergistic Effect of Graphene Nanosheet and $\mathrm{BaTiO}_{3}$ Nanoparticles on Performance Enhancement of Electrospun PVDF Nanofiber Mat for Flexible Piezoelectric Nanogenerators. Nano Energy 2018, 52, 153-162. [CrossRef]

51. Yu, J.; Hou, X.; Cui, M.; Zhang, N.; Zhang, S.; He, J.; Chou, X. Skin-Conformal BaTiO 3 /Ecoflex-Based Piezoelectric Nanogenerator for Self-Powered Human Motion Monitoring. Mater. Lett. 2020, 269, 127686. [CrossRef]

52. Zhang, W.; Yang, H.; Li, L.; Lin, S.; Ji, P.; Hu, C.; Zhang, D.; Xi, Y. Flexible Piezoelectric Nanogenerators Based on a CdS Nanowall for Self-Powered Sensors. Nanotechnology 2020, 31, 385401. [CrossRef] [PubMed]

53. Zhang, Z.; Chen, Y.; Guo, J. ZnO Nanorods Patterned-Textile Using a Novel Hydrothermal Method for Sandwich StructuredPiezoelectric Nanogenerator for Human Energy Harvesting. Phys. E Low-Dimens. Syst. Nanostruct. 2019, 105, 212-218. [CrossRef]

54. Dai, Q.; Pan, P.; Zhang, R.; Liu, J.; Yang, Z.; Wei, J.; Yuan, Q. A Screen-Printed Piezoelectric Energy Harvester Using Zno Tetrapod Arrays. Mater. Technol. 2018, 52, 231-234. 
55. Wang, Y.; Zhang, X.; Guo, X.; Li, D.; Cui, B.; Wu, K.; Yun, J.; Mao, J.; Xi, L.; Zuo, Y. Hybrid Nanogenerator of BaTiO3 Nanowires and CNTs for Harvesting Energy. J. Mater. Sci. 2018, 53, 13081-13089. [CrossRef]

56. Jella, V.; Ippili, S.; Yoon, S.-G. Halide (Cl/Br)-Incorporated Organic-Inorganic Metal Trihalide Perovskite Films: Study and Investigation of Dielectric Properties and Mechanical Energy Harvesting Performance. ACS Appl. Electron. Mater. 2020, 2, 2579-2590. [CrossRef]

57. Fan, F.-R.; Tian, Z.-Q.; Lin Wang, Z. Flexible Triboelectric Generator. Nano Energy 2012, 1, 328-334. [CrossRef]

58. An, T.; Anaya, D.V.; Gong, S.; Yap, L.W.; Lin, F.; Wang, R.; Yuce, M.R.; Cheng, W. Self-Powered Gold Nanowire Tattoo Triboelectric Sensors for Soft Wearable Human-Machine Interface. Nano Energy 2020, 77, 105295. [CrossRef]

59. Kim, J.; Cho, H.; Han, M.; Jung, Y.; Kwak, S.S.; Yoon, H.J.; Park, B.; Kim, H.; Kim, H.; Park, J.; et al. Ultrahigh Power Output from Triboelectric Nanogenerator Based on Serrated Electrode via Spark Discharge. Adv. Energy Mater. 2020, 10. [CrossRef]

60. Ra, Y.; Choi, J.H.; Choi, S.J.; La, M.; Park, S.J.; Kim, M.J.; Choi, D. Cold Rolled Robust Metal Assisted Triboelectric Nanogenerator for Extremely Durable Operation. Extrem. Mech. Lett. 2020, 40, 100910. [CrossRef]

61. Niu, L.; Miao, X.; Jiang, G.; Wan, A.; Li, Y.; Liu, Q. Biomechanical Energy Harvest Based on Textiles Used in Self-Powering Clothing. J. Eng. Fiber. Fabr. 2020, 15. [CrossRef]

62. Bayan, S.; Bhattacharya, D.; Mitra, R.K.; Ray, S.K. Two-Dimensional Graphitic Carbon Nitride Nanosheets: A Novel Platform for Flexible, Robust and Optically Active Triboelectric Nanogenerators. Nanoscale 2020, 12, 21334-21343. [CrossRef] [PubMed]

63. Zou, H.; Guo, L.; Xue, H.; Zhang, Y.; Shen, X.; Liu, X.; Wang, P.; He, X.; Dai, G.; Jiang, P.; et al. Quantifying and Understanding the Triboelectric Series of Inorganic Non-Metallic Materials. Nat. Commun. 2020, 11. [CrossRef] [PubMed]

64. Yuan, F.; Liu, S.; Zhou, J.; Fan, X.; Wang, S.; Gong, X. A Smart Kevlar-Based Triboelectric Nanogenerator with Enhanced Anti-Impact and Self-Powered Sensing Properties. Smart Mater. Struct. 2020, 29, 125007. [CrossRef]

65. Salauddin, M.; Rana, S.M.S.; Sharifuzzaman, M.; Rahman, M.T.; Park, C.; Cho, H.; Maharjan, P.; Bhatta, T.; Park, J.Y. A Novel MXene/Ecoflex Nanocomposite-Coated Fabric as a Highly Negative and Stable Friction Layer for High-Output Triboelectric Nanogenerators. Adv. Energy Mater. 2020. [CrossRef]

66. Sahu, M.; Vivekananthan, V.; Hajra, S.; Abisegapriyan, K.S.; Maria Joseph Raj, N.P.; Kim, S.J. Synergetic Enhancement of Energy Harvesting Performance in Triboelectric Nanogenerator Using Ferroelectric Polarization for Self-Powered IR Signaling and Body Activity Monitoring. J. Mater. Chem. A 2020, 8, 22257-22268. [CrossRef]

67. Mariappan, V.K.; Krishnamoorthy, K.; Pazhamalai, P.; Natarajan, S.; Sahoo, S.; Nardekar, S.S.; Kim, S.J. Antimonene Dendritic Nanostructures: Dual-Functional Material for High-Performance Energy Storage and Harvesting Devices. Nano Energy 2020, 77, 105248. [CrossRef]

68. Qu, X.; Ma, X.; Shi, B.; Li, H.; Zheng, L.; Wang, C.; Liu, Z.; Fan, Y.; Chen, X.; Li, Z.; et al. Refreshable Braille Display System Based on Triboelectric Nanogenerator and Dielectric Elastomer. Adv. Funct. Mater. 2020. [CrossRef]

69. Su, M.; Kim, B. Silk Fibroin-Carbon Nanotube Composites Based Fiber Substrated Wearable Triboelectric Nanogenerator. ACS Appl. Nano Mater. 2020, 3, 9759-9770. [CrossRef]

70. Pu, X.; Liu, M.; Chen, X.; Sun, J.; Du, C.; Zhang, Y.; Zhai, J.; Hu, W.; Wang, Z.L. Ultrastretchable, Transparent Triboelectric Nanogenerator as Electronic Skin for Biomechanical Energy Harvesting and Tactile Sensing. Sci. Adv. 2017, 3, e1700015. [CrossRef]

71. He, X.; Zi, Y.; Guo, H.; Zheng, H.; Xi, Y.; Wu, C.; Wang, J.; Zhang, W.; Lu, C.; Wang, Z.L. A Highly Stretchable Fiber-Based Triboelectric Nanogenerator for Self-Powered Wearable Electronics. Adv. Funct. Mater. 2017, 27. [CrossRef]

72. Pu, X.; Li, L.; Song, H.; Du, C.; Zhao, Z.; Jiang, C.; Cao, G.; Hu, W.; Wang, Z.L. A Self-Charging Power Unit by Integration of a Textile Triboelectric Nanogenerator and a Flexible Lithium-Ion Battery for Wearable Electronics. Adv. Mater. 2015, 27, 2472-2478. [CrossRef] [PubMed]

73. Park, J.; Kim, D.; Kim, Y.T. Ultra-Stretchable on-Body-Based Soft Triboelectric Nanogenerator for Electronic Skin. Smart Mater. Struct. 2020, 29, 115031. [CrossRef]

74. Xu, Y.; Min, G.; Gadegaard, N.; Dahiya, R.; Mulvihill, D.M. A Unified Contact Force-Dependent Model for Triboelectric Nanogenerators Accounting for Surface Roughness. Nano Energy 2020, 76, 105067. [CrossRef]

75. He, T.; Wang, H.; Wang, J.; Tian, X.; Wen, F.; Shi, Q.; Ho, J.S.; Lee, C. Self-Sustainable Wearable Textile Nano-Energy Nano-System (NENS) for Next-Generation Healthcare Applications. Adv. Sci. 2019, 6, 1901437. [CrossRef]

76. Jiang, Y.; Dong, K.; Li, X.; An, J.; Wu, D.; Peng, X.; Yi, J.; Ning, C.; Cheng, R.; Yu, P.; et al. Stretchable, Washable, and Ultrathin Triboelectric Nanogenerators as Skin-Like Highly Sensitive Self-Powered Haptic Sensors. Adv. Funct. Mater. 2020, $31,2005584$. [CrossRef]

77. Tayyab, M.; Wang, J.; Wang, J.; Maksutoglu, M.; Yu, H.; Sun, G.; Yildiz, F.; Eginligil, M.; Huang, W. Enhanced Output in Polyvinylidene Fluoride Nanofibers Based Triboelectric Nanogenerator by Using Printer Ink as Nano-Fillers. Nano Energy 2020, 77, 105178. [CrossRef]

78. Jin, L.; Xiao, X.; Deng, W.; Nashalian, A.; He, D.; Raveendran, V.; Yan, C.; Su, H.; Chu, X.; Yang, T.; et al. Manipulating Relative Permittivity for High-Performance Wearable Triboelectric Nanogenerators. Nano Lett. 2020. [CrossRef]

79. Wang, N.; Wang, X.-X.; Yan, K.; Song, W.; Fan, Z.; Yu, M.; Long, Y.-Z. Anisotropic Triboelectric Nanogenerator Based on Ordered Electrospinning. ACS Appl. Mater. Interfaces 2020, 12, 46205-46211. [CrossRef]

80. Park, K.-I.; Jeong, C.K.; Kim, N.K.; Lee, K.J. Stretchable Piezoelectric Nanocomposite Generator. Nano Converg. 2016. [CrossRef]

81. Dong, S.; Xu, F.; Sheng, Y.; Guo, Z.; Pu, X.; Liu, Y. Seamlessly Knitted Stretchable Comfortable Textile Triboelectric Nanogenerators for E-Textile Power Sources. Nano Energy 2020, 78, 105327. [CrossRef] 
82. Gong, H.; Xu, Z.; Yang, Y.; Xu, Q.; Li, X.; Cheng, X.; Huang, Y.; Zhang, F.; Zhao, J.; Li, S.; et al. Transparent, Stretchable and Degradable Protein Electronic Skin for Biomechanical Energy Scavenging and Wireless Sensing. Biosens. Bioelectron. 2020, 169, 112567. [CrossRef] [PubMed]

83. Pan, C.; Liu, D.; Ford, M.J.; Majidi, C. Ultrastretchable, Wearable Triboelectric Nanogenerator Based on Sedimented Liquid Metal Elastomer Composite. Adv. Mater. Technol. 2020, 5. [CrossRef]

84. Bai, Z.; Xu, Y.; Li, J.; Zhu, J.; Gao, C.; Zhang, Y.; Wang, J.; Guo, J. An Eco-Friendly Porous Nanocomposite Fabric-Based Triboelectric Nanogenerator for Efficient Energy Harvesting and Motion Sensing. ACS Appl. Mater. Interfaces 2020, 12, 42880-42890. [CrossRef] [PubMed]

85. Zhu, Q.; Dong, L.; Zhang, J.; Xu, K.; Zhang, Y.; Shi, H.; Lu, H.; Wu, Y.; Zheng, H.; Wang, Z. All-in-One Hybrid Tribo/Piezoelectric Nanogenerator with the Point Contact and Its Adjustable Charge Transfer by Ferroelectric Polarization. Ceram. Int. 2020, 46, 28277-28284. [CrossRef]

86. Guo, Y.; Zhang, X.S.; Wang, Y.; Gong, W.; Zhang, Q.; Wang, H.; Brugger, J. All-Fiber Hybrid Piezoelectric-Enhanced Triboelectric Nanogenerator for Wearable Gesture Monitoring. Nano Energy 2018, 48, 152-160. [CrossRef]

87. Zhu, J.; Zhu, Y.; Wang, X. A Hybrid Piezoelectric and Triboelectric Nanogenerator with PVDF Nanoparticles and Leaf-Shaped Microstructure PTFE Film for Scavenging Mechanical Energy. Adv. Mater. Interfaces 2018, 5. [CrossRef]

88. Zhu, J.; Hou, X.; Niu, X.; Guo, X.; Zhang, J.; He, J.; Guo, T.; Chou, X.; Xue, C.; Zhang, W. The D-Arched Piezoelectric-Triboelectric Hybrid Nanogenerator as a Self-Powered Vibration Sensor. Sens. Actuators A Phys. 2017, 263, 317-325. [CrossRef]

89. Chen, X.; Song, Y.; Su, Z.; Chen, H.; Cheng, X.; Zhang, J.; Han, M.; Zhang, H. Flexible Fiber-Based Hybrid Nanogenerator for Biomechanical Energy Harvesting and Physiological Monitoring. Nano Energy 2017, 38, 43-50. [CrossRef]

90. Lee, D.W.; Jeong, D.G.; Kim, J.H.; Kim, H.S.; Murillo, G.; Lee, G.H.; Song, H.C.; Jung, J.H. Polarization-Controlled PVDF-Based Hybrid Nanogenerator for an Effective Vibrational Energy Harvesting from Human Foot. Nano Energy 2020, 76, 105066. [CrossRef]

91. Wang, W.; Zhang, J.; Zhang, Y.; Chen, F.; Wang, H.; Wu, M.; Li, H.; Zhu, Q.; Zheng, H.; Zhang, R. Remarkably Enhanced Hybrid Piezo/Triboelectric Nanogenerator via Rational Modulation of Piezoelectric and Dielectric Properties for Self-Powered Electronics. Appl. Phys. Lett. 2020, 116, 023901. [CrossRef]

92. Li, M.; Jie, Y.; Shao, L.H.; Guo, Y.; Cao, X.; Wang, N.; Wang, Z.L. All-in-One Cellulose Based Hybrid Tribo/Piezoelectric Nanogenerator. Nano Res. 2019, 12, 1831-1835. [CrossRef]

93. Rasel, M.S.; Maharjan, P.; Park, J.Y. Hand Clapping Inspired Integrated Multilayer Hybrid Nanogenerator as a Wearable and Universal Power Source for Portable Electronics. Nano Energy 2019, 63, 103816. [CrossRef]

94. Chowdhury, A.R.; Abdullah, A.M.; Hussain, I.; Lopez, J.; Cantu, D.; Gupta, S.K.; Mao, Y.; Danti, S.; Uddin, M.J. Lithium Doped Zinc Oxide Based Flexible Piezoelectric-Triboelectric Hybrid Nanogenerator. Nano Energy 2019, 61, 327-336. [CrossRef]

95. Lapčinskis, L.; Mā Lnieks, K.; Linarts, A.; Blū Ms, J.; Šmits, K.N.; Järvekülg, M.; Knite, M.R.; Šutka, A. Hybrid Tribo-Piezo-Electric Nanogenerator with Unprecedented Performance Based on Ferroelectric Composite Contacting Layers. ACS Appl. Energy Mater. 2019, 2, 4027-4032. [CrossRef]

96. Singh, H.H.; Khare, N. Flexible ZnO-PVDF/PTFE Based Piezo-Tribo Hybrid Nanogenerator. Nano Energy 2018, 51, $216-222$. [CrossRef]

97. Song, J.; Yang, B.; Zeng, W.; Peng, Z.; Lin, S.; Li, J.; Tao, X. Highly Flexible, Large-Area, and Facile Textile-Based Hybrid Nanogenerator with Cascaded Piezoelectric and Triboelectric Units for Mechanical Energy Harvesting. Adv. Mater. Technol. 2018, 3. [CrossRef]

98. Jo, S.; Kim, I.; Byun, J.; Jayababu, N.; Kim, D. Boosting a Power Performance of a Hybrid Nanogenerator via Frictional Heat Combining a Triboelectricity and Thermoelectricity toward Advanced Smart Sensors. Adv. Mater. Technol. 2020, 6, 2000752. [CrossRef]

99. Wu, Y.; Kuang, S.; Li, H.; Wang, H.; Yang, R.; Zhai, Y.; Zhu, G.; Wang, Z.L. Triboelectric-Thermoelectric Hybrid Nanogenerator for Harvesting Energy from Ambient Environments. Adv. Mater. Technol. 2018, 3, 1800166. [CrossRef]

100. Jung, S.; Oh, J.; Yang, U.J.; Lee, S.M.; Lee, J.; Jeong, M.; Cho, Y.; Kim, S.; Baik, J.M.; Yang, C. 3D Cu Ball-Based Hybrid Triboelectric Nanogenerator with Non-Fullerene Organic Photovoltaic Cells for Self-Powering Indoor Electronics. Nano Energy 2020, 77,105271 [CrossRef]

101. Cho, Y.; Lee, S.; Hong, J.; Pak, S.; Hou, B.; Lee, Y.W.; Jang, J.E.; Im, H.; Sohn, J.I.; Cha, S.; et al. Sustainable Hybrid Energy Harvester Based on Air Stable Quantum Dot Solar Cells and Triboelectric Nanogenerator. J. Mater. Chem. A 2018, 6, 12440-12446. [CrossRef]

102. Liu, X.; Li, J.; Fang, Z.; Wang, C.; Shu, L.; Han, J. Ultraviolet-Protecting, Flexible and Stable Photovoltaic-Assisted Piezoelectric Hybrid Unit Nanogenerator for Simultaneously Harvesting Ultraviolet Light and Mechanical Energies. J. Mater. Sci. 2020, 55, 15222-15237. [CrossRef]

103. Zhong, Y.; Zhao, H.; Guo, Y.; Rui, P.; Shi, S.; Zhang, W.; Liao, Y.; Wang, P.; Wang, Z.L. An Easily Assembled ElectromagneticTriboelectric Hybrid Nanogenerator Driven by Magnetic Coupling for Fluid Energy Harvesting and Self-Powered Flow Monitoring in a Smart Home/City. Adv. Mater. Technol. 2019, 4. [CrossRef]

104. Chen, Y.L.; Liu, D.; Wang, S.; Li, Y.F.; Zhang, X.S. Self-Powered Smart Active RFID Tag Integrated with Wearable Hybrid Nanogenerator. Nano Energy 2019, 64. [CrossRef]

105. Ahmed, R.; Kim, Y.; Mehmood, M.U.; Zeeshan; Shaislamov, U.; Chun, W. Power Generation by a Thermomagnetic Engine by Hybrid Operation of an Electromagnetic Generator and a Triboelectric Nanogenerator. Int. J. Energy Res. 2019, 43, 5852-5863. [CrossRef] 
106. Rodrigues, C.; Gomes, A.; Ghosh, A.; Pereira, A.; Ventura, J. Power-Generating Footwear Based on a Triboelectric-ElectromagneticPiezoelectric Hybrid Nanogenerator. Nano Energy 2019, 62, 660-666. [CrossRef]

107. He, J.; Wen, T.; Qian, S.; Zhang, Z.; Tian, Z.; Zhu, J.; Mu, J.; Hou, X.; Geng, W.; Cho, J.; et al. Triboelectric-PiezoelectricElectromagnetic Hybrid Nanogenerator for High-Efficient Vibration Energy Harvesting and Self-Powered Wireless Monitoring System. Nano Energy 2018, 43, 326-339. [CrossRef]

108. Ahmed, R.; Kim, Y.; Zeeshan; Chun, W. Development of a Tree-Shaped Hybrid Nanogenerator Using Flexible Sheets of Photovoltaic and Piezoelectric Films. Energies 2019, 12, 229. [CrossRef]

109. Santiago-Malagón, S.; Río-Colín, D.; Azizkhani, H.; Aller-Pellitero, M.; Guirado, G.; del Campo, F.J. A Self-Powered Skin-Patch Electrochromic Biosensor. Biosens. Bioelectron. 2021, 175, 112879. [CrossRef]

110. Han, Q.; Wang, H.; Wu, D.; Wei, Q. Preparation of PbS NPs/RGO/NiO Nanosheet Arrays Heterostructure: Function-Switchable Self-Powered Photoelectrochemical Biosensor for $\mathrm{H}_{2} \mathrm{O}_{2}$ and Glucose Monitoring. Biosens. Bioelectron. 2021, 173, 112803. [CrossRef]

111. Wardak, C.; Paczosa-Bator, B.; Malinowski, S. Application of Cold Plasma Corona Discharge in Preparation of Laccase-Based Biosensors for Dopamine Determination. Mater. Sci. Eng. C 2020, 116, 111199. [CrossRef] [PubMed]

112. Malinowski, S.; Wardak, C.; Jaroszyńska-Wolińska, J.; Herbert, P.A.F.; Pietrzak, K. New Electrochemical Laccase-Based Biosensor for Dihydroxybenzene Isomers Determination in Real Water Samples. J. Water Process Eng. 2020, 34, 101150. [CrossRef]

113. Malinowski, S.; Wardak, C.; Pietrzak, K. Effect of Multi-Walled Carbon Nanotubes on Analytical Parameters of Laccase-Based Biosensors Received by Soft Plasma Polymerization Technique. IEEE Sens. J. 2020, 20, 8423-8428. [CrossRef]

114. Li, X.; Feng, Q.; Lu, K.; Huang, J.; Zhang, Y.; Hou, Y.; Qiao, H.; Li, D.; Wei, Q. Encapsulating Enzyme into Metal-Organic Framework during in-Situ Growth on Cellulose Acetate Nanofibers as Self-Powered Glucose Biosensor. Biosens. Bioelectron. 2021, 171, 112690. [CrossRef] [PubMed]

115. Wen, F.; He, T.; Liu, H.; Chen, H.Y.; Zhang, T.; Lee, C. Advances in Chemical Sensing Technology for Enabling the Next-Generation Self-Sustainable Integrated Wearable System in the IoT Era. Nano Energy 2020, 78, 105155. [CrossRef]

116. Shi, B.; Li, Z.; Fan, Y. Implantable Energy-Harvesting Devices. Adv. Mater. 2018, 30, 1801511. [CrossRef]

117. Zhang, H.; Yang, Y.; Hou, T.C.; Su, Y.; Hu, C.; Wang, Z.L. Triboelectric Nanogenerator Built inside Clothes for Self-Powered Glucose Biosensors. Nano Energy 2013, 2, 1019-1024. [CrossRef]

118. Xue, X.; Qu, Z.; Fu, Y.; Yu, B.; Xing, L.; Zhang, Y. Self-Powered Electronic-Skin for Detecting Glucose Level in Body Fluid Basing on Piezo-Enzymatic-Reaction Coupling Process. Nano Energy 2016, 26, 148-156. [CrossRef]

119. Jung, Y.K.; Kim, K.N.; Baik, J.M.; Kim, B.S. Self-Powered Triboelectric Aptasensor for Label-Free Highly Specific Thrombin Detection. Nano Energy 2016, 30, 77-83. [CrossRef]

120. Collins, C.M.; Yui, S.; Roberts, C.E.S.; Kojic, I. Thrombin Detection Using a Piezoelectric Aptamer-Linked Immunosorbent Assay. Anal. Biochem. 2013, 443, 97-103. [CrossRef]

121. Antiochia, R. Developments in Biosensors for CoV Detection and Future Trends. Biosens. Bioelectron. 2021, 173, 112777. [CrossRef]

122. Srivastava, A.K.; Dwivedi, N.; Dhand, C.; Khan, R.; Sathish, N.; Gupta, M.K.; Kumar, R.; Kumar, S. Potential of Graphene-Based Materials to Combat COVID-19: Properties, Perspectives, and Prospects. Mater. Today Chem. 2020, 18, 100385. [CrossRef] [PubMed]

123. Li, H.; Koh, C.S.L.; Lee, Y.H.; Zhang, Y.; Phan-Quang, G.C.; Zhu, C.; Liu, Z.; Chen, Z.; Sim, H.Y.F.; Lay, C.L.; et al. A Wearable Solar-Thermal-Pyroelectric Harvester: Achieving High Power Output Using Modified RGO-PEI and Polarized PVDF. Nano Energy 2020, 73, 104723. [CrossRef]

124. Oliveira, H.P.; De Sydlik, S.A.; Swager, T.M.; Helinando, P.; de Oliveira, S.A.S.; Timothy, M. Supercapacitors from Free-Standing Polypyrrole/Graphene Nanocomposites. J. Phys. Chem. C 2013, 117, 10270-10276. [CrossRef]

125. Alcaraz-Espinoza, J.J.; De Melo, C.P.; De Oliveira, H.P. Fabrication of Highly Flexible Hierarchical Polypyrrole/Carbon Nanotube on Eggshell Membranes for Supercapacitors. ACS Omega 2017, 2, 2866-2877. [CrossRef] [PubMed]

126. Lima, R.M.A.P.; Alcaraz-Espinoza, J.J.; Da Silva, F.A.G.; De Oliveira, H.P. Multifunctional Wearable Electronic Textiles Using Cotton Fibers with Polypyrrole and Carbon Nanotubes. ACS Appl. Mater. Interfaces 2018, 10, 13783-13795. [CrossRef]

127. Alcaraz-Espinoza, J.J.; de Oliveira, H.P. Flexible Supercapacitors Based on a Ternary Composite of Polyaniline/Polypyrrole/Graphite on Gold Coated Sandpaper. Electrochim. Acta 2018, 274, 200-207. [CrossRef]

128. Shi, X.; Chen, S.; Zhang, H.; Jiang, J.; Ma, Z.; Gong, S. Portable Self-Charging Power System via Integration of a Flexible Paper-Based Triboelectric Nanogenerator and Supercapacitor. ACS Sustain. Chem. Eng. 2019, 7, 18657-18666. [CrossRef]

129. Mule, A.R.; Dudem, B.; Patnam, H.; Graham, S.A.; Yu, J.S. Wearable Single-Electrode-Mode Triboelectric Nanogenerator via Conductive Polymer-Coated Textiles for Self-Power Electronics. ACS Sustain. Chem. Eng. 2019, 7, 16450-16458. [CrossRef]

130. He, H.; Zhang, M.; Zhao, T.; Zeng, H.; Xing, L.; Xue, X. A Self-Powered Gas Sensor Based on PDMS/Ppy Triboelectric-Gas-Sensing Arrays for the Real-Time Monitoring of Automotive Exhaust Gas at Room Temperature. Sci. China Mater. 2019, 62, 1433-1444. [CrossRef]

131. Shi, Z.; Zhou, H.; Qing, X.; Dai, T.; Lu, Y. Facile Fabrication and Characterization of Poly(Tetrafluoroethylene) @polypyrrole/NanoSilver Composite Membranes with Conducting and Antibacterial Property. Appl. Surf. Sci. 2012, 258, 6359-6365. [CrossRef]

132. Kumar, R.; Pandey, A.K.; Singh, R.; Kumar, V. On Nano Polypyrrole and Carbon Nano Tube Reinforced PVDF for 3D Printing Applications: Rheological, Thermal, Electrical, Mechanical, Morphological Characterization. J. Compos. Mater. 2020, 54, 4677-4689. [CrossRef] 